This is an electronic reprint of the original article. This reprint may differ from the original in pagination and typographic detail.

Author(s): Virtanen, Tuomo; Lerkkanen, Marja-Kristiina; Poikkeus, Anna-Maija; Kuorelahti, Matti

Title: $\quad$ The relationship between classroom quality and students' engagement in secondary school

Year: $\quad 2015$

Version:

Please cite the original version:

Virtanen, T., Lerkkanen, M.-K., Poikkeus, A.-M., \& Kuorelahti, M. (2015). The relationship between classroom quality and students' engagement in secondary school. Educational Psychology, 35(8), 963-983.

https://doi.org/10.1080/01443410.2013.822961

All material supplied via JYX is protected by copyright and other intellectual property rights, and duplication or sale of all or part of any of the repository collections is not permitted, except that material may be duplicated by you for your research use or educational purposes in electronic or print form. You must obtain permission for any other use. Electronic or print copies may not be offered, whether for sale or otherwise to anyone who is not an authorised user. 
The Relationship between Classroom Quality and Students' Engagement in Secondary School 


\begin{abstract}
Student engagement has been identified as an influential mediator between classroom interactional quality and adolescent learning outcomes. This study examined the relationship between classroom quality and student behavioral engagement in secondary school classrooms. Three dimensions of classroom quality (emotional, organizational, and instructional support) and the dimension of student engagement were observed in nine classrooms using the Classroom Assessment Scoring System. Self-ratings of behavioral engagement were provided by 181 Finnish secondary school students along with their teachers' ratings of classroom-level student engagement. The results showed, first, that there was variation in both classroom quality and student behavioral engagement between the classrooms. Second, classroom organizational support was associated with observed and with teacher- and student-rated engagement, and instructional support was associated with studentrated and observed engagement. Third, emotional support did not have a direct effect on student engagement but contributed to student engagement indirectly via organizational and instructional support. There were no gender differences with respect to self-reported engagement. Class size had a positive effect on teacher-rated engagement. The results demonstrated specific associations between the domains of classroom quality and student behavioral engagement in secondary school classrooms.
\end{abstract}

Keywords: student engagement, classroom quality, classroom observations, secondary school 


\section{The Relationship between Classroom Quality and Students' Engagement in Secondary School}

Student engagement, implying commitment and investment in learning and school life, is believed to be the main contributor to students' concurrent and subsequent academic success (e.g., Skinner, Furrer, Marchand, \& Kindermann, 2008). Engagement is documented to predict patterns of attendance, and academic resilience, whereas lack of student engagement can have serious consequences, such as underachievement, deviant behaviors, and dropping out of school (Finn \& Rock, 1997). A decline in student engagement with schooling appears to take place during the transition from primary to secondary education (Skinner et al., 2008) particularly among boys (Wigfield, Eccles, Schiefele, Roeser, \& DavisKean, 2006). To understand the processes behind the pattern of waning engagement and its relation with classroom quality in secondary school, analyses are needed which combine observational data on classroom interactional processes and both teachers' and students' ratings of student engagement in classroom activities and learning tasks. Consequently, the present study contributes to the educational field and understanding of classroom practices fostering student engagement by investigating the relationship between observed classroom quality and students' self-reported, teacher-reported, and observed behavioral engagement in the context of secondary school classrooms. .

\section{Student Engagement}

Student engagement is a concept that taps students' school experiences and their relationship with school (Libbey, 2004). It has been studied from many viewpoints: as a means of preventing dropping out of school (Finn \& Rock, 1997), as a moderator of gaps in learning (Woolley \& Bowen, 2007), and as an outward manifestation of motivation (Skinner, 
Kindermann \& Furrer, 2009). Typically, student engagement is conceptualized along three dimensions or components: emotional component is seen to encompass aspects of a student's relationship with teachers and peers, sense of belonging, and enjoyment during learning activities. Behavioral engagement is described in terms of persistence, participation, and task behavior. The cognitive component, in turn is conceptualized in terms of motivation, selfregulation, and learning styles (see Fredricks, Blumenfeld, \& Paris, 2004; Glanville \& Wildhagen, 2007; Libbey, 2004; Skinner \& Pitzer, 2012). Student engagement can be seen as both an indicator of effectiveness of classroom quality and a mediator between classroom processes and students' learning outcomes. The literature indicates that students with a high sense of belonging, perception of support by teachers and peers, and positive expectations manifest higher behavioral engagement with schooling and obtain good learning outcomes (Woolley \& Bowen, 2007). The seminal work by Finn (1989) saw student participation in classroom activities (behavioral engagement) as a starting point for good grades and identification with school (emotional engagement). Taking the view of behavioral engagement, the focus of this study, emphasizes learning through participation and taskfocused action in the classrooms, but it does not undermine the relevance of other components of engagement and their strong links.

Li, Lerner, and Lerner (2010) showed that at the individual level, student behavioral engagement at Grade 5 was directly associated with academic competence at Grade 6.

Decline in academic competence and future educational plans have been found to be most marked for adolescents with reduced school participation (behavioral engagement) and selfregulated learning (Wang \& Eccles, 2012). Hattie (2009) reported in his synthesis of metaanalyses that student concentration, persistence, and engagement have a mean effect size of .48 on student achievement. Inattentive-withdrawn behavior, in turn, has been shown to be associated with depressed academic performance (Finn \& Pannozzo, 1995). There is also 
evidence to show that only student behavioral engagement alone predicts subsequent school dropout (Archambault, Janosz, Fallu, \& Pagani, 2009). With respect to gender differences, students' self-ratings (Covell, 2010; Wang, Willett, \& Eccles, 2011) have indicated that girls are more behaviorally engaged than boys.

At classroom-level, the collective behavioral engagement of the students represents one domain of overall classroom quality (Pianta, Hamre, \& Mintz, 2010). Classroom behavioral engagement is seen as a mediator between teacher-led classroom processes and students' learning outcomes (Pianta, Hamre, \& Allen, 2012). Classrooms with high overall taskorientation increase student opportunities to learn (i.e., engaged time of students) which is a necessary condition for learning to take place (Mitchell, 2008). This permits teacher resources to be used more effectively for emotionally and instructionally supportive interactions (instead of classroom management) which contributes to student learning. Behavioral engagement presents a low inference type of engagement (Fredricks et al., 2004) observable at the classroom-level. Based on the level of classroom behavioral engagement, teachers can identify engaging classroom practices and change the instruction accordingly.

There is conflicting evidence on whether smaller classrooms increase the likelihood of high student behavioral engagement in the secondary classroom. Gilstrap (2003) rated the overall level of the classroom engagement of students in Grades 7 and 8 and found greater student engagement in smaller classrooms. However, in another study (Malmberg, Hagger, Burn, Mutton \& Colls, 2010), secondary school students' classroom-level behavioral engagement was higher in larger classrooms than in smaller classrooms. Sometimes the positive effect of class size on student engagement has been found only for low-attaining secondary school students (Blatchford, Bassett, \& Brown, 2011). In sum, these results show that student behavioral engagement is closely associated with educational outcomes such as 
student academic achievement and completing school. It is also a practical indicator of the successfulness of classroom practices.

Student engagement is assumed to be responsive to the characteristics of and changes in the learning environment, such as dimensions of classroom processes (Pianta et al., 2012). It has practical applicability as a concept, as it directs educators' attention to malleable contextual factors instead of students' backgrounds (Marks, 2000). Instead of referring primarily to the trait of an individual, engagement refers to the interaction between an individual's characteristics and his/her environment (Thijs \& Verkuyten, 2009). Educators are constantly searching for qualities of classroom interactions that facilitate students' individual and classroom-level behavioral engagement in learning and prevent disengagement. Accordingly, this study treats classroom behavioral engagement as an outcome of classroom processes and assesses it using student ratings, teacher ratings and classroom-level observations.

Some scholars define behavioral engagement broadly as active participation in schoolrelated activities. For example, Finn $(1989,1993)$ indicated in his participation-identification model that active participation, supported by high-quality instruction, improves academic achievement, and in a reciprocal fashion, academic achievement increases identification (belonging and valuing) with school, which, in turn, increases participation and engagement. Other definition of behavioral engagement include references to school attendance and compliance (Archambault et al., 2009), effort, attention, and persistence during the initiation and execution of learning activities (Marks, 2000; Skinner et al., 2008; Skinner, \& al., 2009), motivated behavior, participation in classroom activities, on-task behavior, task completion (Anderson, Hamilton, \& Hattie, 2004), persistence when facing challenges, and preference for working hard (Skinner \& Pitzer, 2012). 
Previous studies are limited in at least three four ways. First, they have typically utilized individual level student- and/or teacher-report measures of classroom interactions (Furrer \& Skinner, 2003), and thus conclusions on overall classroom quality and engagement have been filtered through the perceptions of classroom participants. Employment of observations of authentic classroom interactions has the potential of providing a comprehensive view of classroom behavioral engagement in secondary classrooms. Observations provide understanding of the qualities of instructional practices that foster taskorientation and participatory learning environments for all students. It is acknowledged that classroom processes can be interpreted in different ways, depending on the informant (Appleton \& Lawrenz, 2011), which makes it important to use several sources of information. Second, observational studies are scarce in secondary classrooms (for an exception, see Allen, Gregory, Mikami, Lun, Hamre \& Pianta, 2010), where understanding of the mechanisms behind waning engagement is most urgently needed. Finally, previous studies have not, as far as we know, revealed the mechanisms through which the observed classroom interactions are associated with student- and classroom level behavioral engagement. The study aims to address the above mentioned limitations of previous research in the following way. First, in addition to student- and teacher ratings of engagement, the study involves direct classroom observations. Second, the study is conducted in secondary school context where observation studies are scarce. Third, the study focuses on the associations between observed classroom interactions and student- and classroom behavioral engagement aiming to fill the current research gap.

\section{Classroom Quality}

Interactions between teacher and students and among students are the primary source of student development (Pianta \& Allen, 2007), and, thus, how the teacher structures the learning environment to promote these interactions becomes of central importance. Research 
using systematic observations of student-teacher interaction has differentiated three relational domains of classroom quality: emotional support, classroom organization, and instructional support (Pianta et. al, 2010). While emotional support is seen as a broad interactional framework, classroom organization and instructional support refer to a set of more explicit teacher-orchestrated actions.

Emotional support is characterized by warm and caring relationships, teacher sensitiveness to students' academic, behavioral and affective needs, and perspectives and ideas. Support for students' social and emotional functioning in the classroom is thought to be reflected in behavioral engagement. Classroom organization refers to the management of students' behavior, time, and attention, with the goal of engaging students in learning activities (Emmer \& Stough, 2001; Evertson \& Weinstein, 2006). Effective behavior management encompasses clear expectations, routines, and rules which are positively reinforced (Gettinger \& Walter, 2012), and the teacher's use of methods to encourage desirable behavior and to prevent and redirect misbehavior, thereby maximizing learning time (Pianta et al., 2010). Finally, instructional support is related to using teaching methods which foster students' use of higher level thinking skills and enable deep processing of materials (Pianta et al., 2010). Effective instructional support includes being aware of aspects students typically misunderstand, transforming content to make it easily accessible to students, presenting key ideas and a broad framework, and using aids such as metaphors, analogies, problems, pictures, and diagrams (Gibbs \& Poskitt, 2010). Previous studies have shown (Hardman, 2008; Mercer \& Littleton, 2007) that one way to provide students with effective instructional support and enhance engagement is using instructional dialogues in the classroom. . Effective teaching is seen as multidimensional construct consisting of high quality interactions along all three domains. 
Previous studies have shown that classroom quality contributes to a range of student outcomes (see Pianta \& Allen, 2007). High quality emotional support in the classroom has been linked with various positive schooling outcomes among adolescents such as subjective well-being (Suldo, Friedrich, White, Farmer, Minch \& Michalowski, 2009), social skills and academic competence (Malecki \& Demaray, 2003), teacher reports of high levels of student participation in class, students' self-reports of engagement and task completion (Anderson et al., 2004), experience of meaningfulness of schoolwork and on-task orientation (Thuen \& Bru, 2000), school satisfaction (Danielsen, 2009; Richman, Rosenfeld, \& Bowen, 1998), students' self-reports of cognitive and behavioral engagement in learning via motivational beliefs (Patrick \& Ryan, 2007), and teacher- and student-reports of behavioral and emotional classroom engagement (Furrer \& Skinner, 2003). Klem and Connell (2004) examined the impact of student-reported teacher support on student engagement (effort and attention in classes, being prepared for classes, and finding school personally important).Their results indicated that engagement in school was higher among elementary and secondary students who were taught by teachers that the students perceived as caring and autonomy supportive, and who created well-structured learning environments. Ryan and Patrick (2001) assessed classroom emotional support using student perceptions of how respectful, responsive, and sensitive their teacher was. Their results revealed that when students perceived that their teacher cared for them, and understood, and supported them, the students' efficacy in communicating and getting along with their teacher was higher, and they also engaged in more self-regulated learning, and less off-task and disruptive behavior in the classroom. In a study drawing from a motivational perspective it was found that the more teacher proximity students experienced, the more pleasure, relevance, and confidence they reported, and the more willing they were to put effort into the subject (den Brok, Levy, Brekelmans, \& Wubbels, 2005). 
Recent reports (Brackett, Reyes, Rivers, Elbertson, \& Salovey, 2011; Reyes, Brackett, Rivers, White, \& Salovey, 2012) utilizing observations of classroom emotional support have provided evidence that emotional support contributes to students' school adjustment. Reyes et al. (2012) documented that classroom emotional support had a positive impact on academic achievement both directly and indirectly mediated by student engagement (students' perceptions of their effort, interest, and enjoyment in learning activities). Bracket et al. (2011) reported that when teacher characteristics and organizational and instructional aspects of the classroom were controlled for, a direct, positive relationship emerged between classroom emotional climate and conduct that also was mediated by teacher affiliation. Although studies on engagement in the middle school years have accumulated in the recent years, studies on observed classroom quality and student engagement continue to be rare at the secondary level. As an exceptional example of the latter, Allen et al. (2010) found observed emotional support in the classroom to be the best predictor of engagement and student achievement (Pianta et al., 2012). Allen and his colleagues concluded that emotional support provided by the teacher can be regarded as an individual teacher quality, and therefore likely to be relatively independent of classroom characteristics. We expected to find that emotional support may serve the purpose of setting the stage for classroom interactions at large, and be a precondition for effective academic instruction and classroom organization. Feeling secure and at ease is necessary for achieving the mental readiness to undertake challenging tasks (see Curby, Grimm, \& Pianta, 2010). Fostering emotional support in the classroom may contribute to enhanced behavioral and cognitive engagement (Li et al., 2010; Walker \& Greene, 2009), given that disengagement is expected to manifest first at the emotional and then at the behavioral level (Eccles, 2004).

Taken together, research indicates that emotional support in the classrooms contributes to various positive schooling outcomes, including student- and teacher-reported behavioral 
engagement in learning. In classrooms with high emotional support, students' fundamental psychological need of relatedness is met (Connell \& Wellborn, 1991; Deci \& Ryan, 2000) which is reflected in student behavioral engagement and successful learning. However, not all secondary students are exposed to high quality teaching and learning, as emotional quality varies greatly between secondary school classrooms (Malmberg et al., 2010) .

\section{Research Questions and Hypotheses}

The present study examined the extent to which observed classroom quality is associated with secondary school students' behavioral engagement in learning. The study aimed to answer the following questions:

(1) Do classrooms differ with respect to three domains of classroom quality? On the basis of previous research in secondary classrooms (e.g., Malmberg et al., 2010), we expected (Hypothesis 1) to find differences between classrooms in observed classroom quality. (2) Do classrooms differ with respect to students' engagement in learning? Previous research has shown that classrooms matter in shaping students' engagement (Connell \& Wellborn, 1991; Deci \& Ryan, 2000; Perry, Turner, \& Meyer, 2006). Accordingly, we expected that classrooms would differ (Hypothesis 2) with respect to student-reported and observed behavioral engagement in learning.

(3) Are there gender differences in students' self-reported behavioral engagement? Previous research has shown that girls manifest higher behavioral engagement than boys (Covell, 2010; Wang et al., 2011). Accordingly, we expected that girls would show higher behavioral engagement than boys in self-reports (Hypothesis 3).

(4) To what extent is observed emotional support in classroom associated with students' behavioral engagement in learning either directly or indirectly via instructional and 
organizational supports? Previous findings have indicated that teacher or student ratings of emotional support in the classroom contribute to students' self-reported, teacher-reported, and observed behavioral engagement in learning (Anderson et al., 2004; Furrer \& Skinner, 2003) and that emotionally supportive interactions (caring, and teacher warmth) lead to positive instructional interactions (Connell \& Wellborn, 1991; Rimm-Kaufman, Fan, Chiu, \& You, 2007; Skinner \& Belmont, 1993). Based on these suggestions in the literature, we hypothesized that emotional support contributes to student engagement both directly and indirectly via instructional and organizational supports (Hypothesis 4).

(5) To what extent is classroom size associated with students' self-reported, teacher-reported, and observed behavioral engagement in learning? Because previous results on the effect of classroom size on student engagement are contradictory (Blatchford et al., 2011; Gilstrap, 2003; Malmberg et al., 2010), we did not posit a hypothesis.

\section{Method}

\section{Participants and procedure}

The present study is a part of national initiative with the aim of implementing the recently modified basic education core curriculum in Finland (Finnish National Board of Education, 2010). Participants were 181 secondary school (41 seventh graders, 63 eighth graders, and 77 ninth graders) students (96 male, 85 female students) and eight teachers (2 males, 6 females) enrolled in four schools and nine classrooms (one of the teachers was teaching two separate classrooms). All the selected schools were participating in the implementation project. Before starting the study, the school principals were contacted, informed about the study, and asked to consent to their school taking part in the study. The teachers and students in the participating schools were recruited for the study on a voluntary basis, and students' parents were also informed about the study. The participating classrooms were from mainstream schools in one medium-sized town and three municipalities located in 
Central Finland, with Finnish as the principal language of instruction. The subjects taught in the classrooms during the observations were Literacy, History and Civics, Biology and Geography, Chemistry, and Home Economics. Each class contained an independent sample of students, that is, the same students were not observed in multiple subjects. Each teacher assessed the level of behavioral engagement in the classroom (i.e., ratings with respect to the classroom as a whole), and 109 students self-rated their behavioral engagement in learning.

The classroom observations were carried out during the end of the autumn term (November - December). The observations were conducted on two different days at an interval of about one week apart four cycles per each classroom. Teachers rated each classroom engagement and the students self-rated their behavioral engagement during the observation period at a time suitable for them.

\section{Measures}

Classroom quality observations. The classrooms were observed using the Classroom Assessment Scoring System (The CLASS-S; Pianta et al., 2010). The CLASS-S consists of 12 items measuring four components of classroom quality: (1) Emotional Support (four items: Positive climate, Negative climate (reversed for analyses), Teacher sensitivity, and Regard for adolescent perspectives), (2) Classroom Organization (three items: Behavior management, Productivity, and Instructional learning formats), (3) Instructional Support (four items: Content understanding, Analysis and problem solving, Quality of feedback, and Instructional dialogue), and (4) Student Engagement (one item). Each item was rated on a 7point scale: low $(1,2)$, moderate $(3-5)$, and high $(6,7)$. The observations focused on overall classroom quality; that is, the quality of teacher-student interactions were assessed at the classroom level and no assessments were made at the level of teacher interactions with individual students. The manual (Pianta et al., 2010) provides detailed information on the 
indicators of each item, along with examples of teacher behaviors and classroom interactions, and reliability and validity information.

In the present study, the 14 observers, all students of Education or Psychology, were carefully prepared with 10 hours of training and three hours of live observation practice during a two-week period in November. In cases where the ratings by a pair of observers showed a discrepancy of more than one point (see Pianta, La Paro, \& Hamre, 2008), extra rating practice in a live classroom situation was required, after which the inter-rater agreement was re-monitored. Extra practice was needed by two pairs of observers. At the end of the training, each pair reached at least $80 \%$ agreement within 1 scale point, and subsequently all observers who had completed the training were allowed to proceed with codings. Inter-rater reliabilities for the actual classroom observations were estimated as ICCs (intra class correlations) between the pairs of observers on the individual ratings. They were calculated as recommended by McGraw and Wong (1996), using a two-way mixed effect model (measure fixed, observers random), the absolute agreement definition, and the average measure intra-class correlation, which assumes no interaction effect. ICCs were high: .77 for emotional and instructional supports, .79 for organizational support, and .82 for student engagement.

In the present study, classroom observations were conducted on two different days. In order to avoid common method variance each classroom was observed by two different pairs of observers. Each observation session lasted one school class with two 30-min observation cycles (total of four cycles per classroom). The observers first observed for a 20-min period while making notes on indicators on a separate sheet of paper, and in the subsequent 10-min period (before beginning the next observation cycle), they recorded their codings on the scoring sheet. The data comprised a total of 72 observation cycles. 
Domain-level summary scores were calculated for each cycle (total 72) by averaging the scores for the dimensions (items) belonging to each specific domain, namely, Emotional support, Classroom organization, and Instructional support. Cronbach's alphas for the classroom quality domains indicated good internal consistency of the scales: Emotional Support $\alpha=.86$, Classroom Organization $\alpha=.72$, and Instructional Support $\alpha=.91$.

Students' behavioral engagement in learning. Behavioral engagement, which was treated as a dependent variable, was assessed using three measures: ratings by the observers at the classroom level, students' self-ratings, and teacher's classroom-level ratings. Ratings derived from the observations using the CLASS-S (Pianta et al., 2010) were used at the classroom level to provide a measure of students' active versus passive engagement in learning activities during the classes. Active engagement was evidenced by students answering and asking questions, and taking part in dialogues and activities.

Students were asked to provide self-ratings of their own task orientation during the classes, using the WIHIC task orientation scale (Fraser, 1998; What is Happening in this Class). The WIHIC questionnaire has been used in several countries and cultural environments (Dorman, 2008; Fraser, Aldridge, \& Adolphe 2010; Waldrip, 2009), and it has proven reliability and validity for assessing students' perceptions of classroom actions (Dorman, 2008). Students' perceptions were assessed with eight items (e.g., "I am attentive during this class") rated on a 5-point rating scale ( 1 = almost never; $5=$ almost always $)$. Cronbach's alpha for the students' self-ratings was .90. The student ratings were aggregated to provide a mean level of student engagement for a particular classroom.

Teachers' perceptions of overall student engagement in the classroom were also assessed using the WIHIC scale (Fraser, 1998). These ratings were given by the teachers at the level of the classroom (i.e., the ratings were given by each teacher for the class they were teaching). The wording of the eight items was modified from the student ratings to 
accommodate the teacher perspective. For example, the student item "I am attentive during this class" was turned into "The students of this classroom are attentive in my classes." Cronbach's alpha for teachers' ratings of students task orientation was .73. The composite value of the eight items rated by each teacher was used as a measure of classroom-level student behavioral engagement in the subsequent analyses.

\section{Analysis Strategy}

The analyses were carried out as follows. First, the preliminary analyses were conducted using SPSS Statistic version 19 to examine the means, standard deviations, and correlations among the classroom quality domains and dimensions, and the correlations between the classroom quality domains and engagement. Second, one-way analysis of variance (ANOVA) was used to examine whether there were classroom differences between the scores for the three domain of classroom quality, student-rated, and observed behavioral engagement (research questions 1 and 2). Gender differences in students' self-reported engagement were investigated with the t-test (research question 3). Finally, the main analyses were conducted in a structural equation modeling $(S E M)$ framework to examine the extent to which the observational scores of classroom quality were associated with the three measures of behavioral engagement. Of special interest were direct and indirect (via classroom organization and instructional support) effects of classroom emotional support on students' engagement (research question 4).

The main analyses (Research Question 4) were performed using the Mplus statistical package (version 6.12: Muthén \& Muthén, 1998-2010). The standard Missing At Random (MAR) approach was applied (Muthén \& Muthén, 1998-2010). The parameters of the models were estimated using the Full Information Maximum Likelihood (FIML) estimation with non-normality robust standard errors (MLR estimator: Muthén \& Muthén, 1998-2010). The goodness-of-fit of the estimated models were evaluated by two absolute fit indices, $\chi^{2}$ and 
Root Mean Square Error of Approximation (RMSEA), and two comparative fit indices, the Comparative Fit Index (CFI) and Tucker Lewis Index (TLI). The cutoff values for wellfitting models were as follows: $\chi^{2}=n s(p>.05)$, RMSEA $<.05$, CFI $>.95$, and TLI $>.95$ (Byrne, 2012). Because multicollinearity between independent variables (three measures of classroom quality) can cause problems in regression analysis, VIF indices were examined. According to the VIF test, all the indices fell below 5, indicating no multicollinearity problems. The unit of analysis was an observation cycle (total 72 cycles). The nested structure of the data (the observation cycles were nested within classrooms) was taken into account by utilizing the Mplus (COMPLEX type analysis) with teacher as a clustering variable (Muthén \& Muthén, 1998-2010).

Statistical significance of the indirect effects from observed classroom emotional support via organizational and instructional support to the measures of behavioral engagement were assessed using bias-corrected $95 \%$ confidence intervals produced by the bootstrapping resampling method (MacKinnon, Lockwood, \& Williams, 2004).

Bootstrapping approach is a reliable method for assessing statistical significance of indirect paths since the approach does not assume that the indirect paths are normally distributed.

\section{Results}

\section{Preliminary analyses}

Means, standard deviations, and bivariate correlations among the classroom quality domains (emotional support, classroom organization, and instructional support) and dimensions (items) are presented in Table 1. Correlations were highest for the dimensions within their respective domains. Emotional support also showed relatively high correlations with dimensions in the instructional support domain (ranging from .61 - .74) and the dimension of instructional learning formats, which belongs to the domain of classroom organization. Instructional support correlated highly with its respective dimensions and with 
the dimensions of regard for adolescents' perspectives (.75), which belongs to the domain of emotional support.

As shown in Table 2, emotional support and instructional support were relatively highly correlated with each other (.75). The three classroom quality domain scores correlated with all three measures of student engagement, with the exception of instructional support and teacher-reported student engagement. The student engagement measures were relatively highly correlated with each other, the largest correlation emerging between student-reported and observed engagement (.52). Teachers perceptions of overall students' classroom engagement and students own ratings showed the least common variance $(\rho=.33)$.

\section{Descriptive analyses}

First, differences between classrooms with respect to the classroom quality domains were examined using one-way analysis of variance (ANOVA). As shown in Table 3, significant differences in classroom quality were found in all domains $(p s<.001)$. Etasquared effect sizes varied between .50 and .58 , indicating large differences in classroom quality according to Cohen's (1988) conventions. Second, the ANOVA indicated significant differences between classrooms in observed $(p<.001)$ and student-reported $(p<.01)$ engagement. The effect sizes, .47 and .18 respectively, indicated large effects (see Table 3). Taken together, the findings indicated that students were exposed to instruction the quality of which varied widely between classrooms. Wide variation was also found between classrooms in students' observed and self-reported behavioral engagement in learning.

Gender differences in self-reported student engagement (RQ 3), were examined using independent samples t-test. The mean score for girls was not significantly higher $(\mathrm{M}=3.59$; $\mathrm{SD}=.78)$ than the mean score for boys $(\mathrm{M}=3.54 ; \mathrm{SD}=.69): t(105)=.30 ; p=.76$ (twotailed). The results thus indicated no gender differences. 


\section{Relation between classroom quality and student engagement}

The fourth research question concerned the extent to which observed emotional support is associated with students' behavioral engagement in learning, either directly or indirectly via instructional and organizational supports. First, a model was constructed where all the possible direct paths from the classroom quality variables (observed classroom emotional support, organizational support, and instructional support) and classroom size to the three dependent variables (student-rated engagement, teacher-rated engagement, and observed engagement) were modeled. Next, all non-significant direct paths were removed one by one. At this point, all the paths from emotional support proved non-significant; however, all the paths from organizational support to the three engagement measures and the path from classroom size to teacher-rated student engagement were significant and positive. The path from instructional support to teacher-rated engagement was non-significant and therefore excluded. The path from instructional support to observed engagement showed a trend $(p=$ $.052)$ and it was included in the analysis. The model fit indices were: $\chi^{2}(9)=6.552, p=.6837$; RMSEA $=.000 ;$ CFI $=1.000 ;$ TLI $=1.044$, indicating good fit to the data.

As shown in Figure 1, observed emotional support operated in concert with the other two classroom quality domains, both of which were positively associated with students' behavioral engagement. The standardized regression coefficients were .52 for organizational support and .73 for instructional support. Emotional support accounted for $27 \%$ and $54 \%$, respectively, of the explained variance of these two domains. Organizational support explained students' behavioral engagement best, given that all the regression paths to student engagement were significant. Class size was not associated with student-rated or observed engagement; however, a positive association emerged between classroom size and teacherrated engagement. The variables in the model explained $34 \%, 44 \%$, and $55 \%$ of the variance of student-rated, teacher-rated, and observed engagement, respectively. 
To obtain the significance of the indirect effects from classroom emotional support to the three measures of behavioral engagement the bootstrap method was applied (MacKinnon, Lockwood, \& Williams, 2004). The coefficients indicating indirect effects from emotional support to observed (estimate $=.54, p<.05,95 \% \mathrm{CI}=.30 ; .80)$ and teacher-rated behavioral engagement (estimate $=.12, p<.05,95 \% \mathrm{CI}=.06 ; .19)$ via organizational support were statistically significant. The indirect path from emotional support to student-rated engagement via organizational support was statistically significant (estimate $=.05, p<.05$, $95 \% \mathrm{CI}=.008 ; .11)$. The indirect path from emotional support to student-rated engagement via instructional support was statistically significant (estimate $=.14, p<.05,95 \% \mathrm{CI}=.07$; .22). The same was true for the path from emotional support to observed engagement via instructional support (estimate $=.19, p<.05,95 \% \mathrm{CI}=.01 ; .39)$.

\section{Discussion}

The aim of the present study was to examine the relationship between observed classroom quality and student's behavioral engagement in secondary school classrooms. It was expected that emotional, organizational and instructional support in the classroom would contribute to student engagement; .i.e., higher classroom quality would facilitate higher student engagement. Based on earlier suggestions in the literature (e.g., Pianta et al., 2012), emotional support was assumed to have both a direct impact on student engagement and to contribute to engagement indirectly by setting the stage for organizational and instructional classroom interactions.

Although school-level variation in student outcomes in Finland is generally small (Sahlberg, 2007), variation in classroom quality was significant in the present study. This result, supporting our hypothesis (Hypothesis 1), is consistent with other findings indicating that secondary students are exposed to differences in the quality of instruction (Malmberg et 
al., 2010). In high quality classrooms, students are likely to have better possibilities to satisfy their basic needs, engage in learning, and develop optimally, whereas low quality classrooms may fail to facilitate optimal development during the critical period of adolescence with waning student engagement (Skinner et al., 2008). High classroom quality nurtures students' behavioral engagement which in turn contributes to student academic achievement and educational aspirations (Wang \& Eccles, 2012). Finn's (1989, 1993) participationidentification model suggests that both strong student behavioral engagement and high quality of instruction serve as protective factors against adolescents' withdrawing from school. Pianta and Allen (2007) note that the core criterion by which secondary classrooms should be judged is the capacity of the classroom setting to engage and motivate youth.

The present study supported our hypothesis 2, viz. that the level of student-reported behavioral engagement and classroom-level behavioral engagement varies between classrooms. This finding is consistent with the notions that classroom environments shape student egagement (e.g., Perry et al., 2006) and that engagement is an indicator of students' school experiences (Skinner \& Pitzer, 2012). The fact that classroom quality was associated with students' self-reported behavioral engagement indicates that support in the classroom nurtures higher levels of behavioral engagement.

With respect to gender differences in behavioral engagement, the findings did not support the hypothesis (Hypothesis 3). Previous studies (Covell, 2010; Wang, Willett, \& Eccles, 2011) have found girls to manifest higher behavioral engagement than boys. In the present study, no gender differences were found in the students' self-ratings of engagement. This may be due to the items used in the present study. When gender differences are found, school-level constructs like school compliance and skipping classes are often, included in the student behavioral engagement construct along with being attentive and staying focused during classes (e.g., Wang et al., 2011). These composite measures may be problematic 
because male students may, for instance, skip classes more than female students but when at a class regard themselves as equally focused as female students. In the present study the focus of the ratings was on classroom behavior which may explain the lack of gender differences.

The results of the present study showed that classrooms observed as high in emotional, instructional and organizational quality were found to have students who were behaviorally highly engaged. That is, classroom quality was associated with student engagement in the expected direction: higher classroom quality was associated with higher observed, studentrated, and teacher-rated engagement. Somewhat surprisingly, emotional support did not have a direct influence on observed, student-reported or teacher-reported engagement. Emotional support was, however, associated with engagement indirectly via organizational and instructional supports, lending partial support to our hypothesis (Hypothesis 4). Previous studies have been based on student- and teacher reports of emotional support (e.g., Anderson et al., 2004; Furrer \& Skinner, 2003), whereas in the present study observations were utilized. Another possible explanation is statistical. As the sample consisted of only 72 observed teaching cycles, it is possible that and the differences between classrooms in emotional support were not robust enough to for statistically significant paths to emerge. Moreover, in secondary school, where classes are taught by subject specialists, the relationship between students and their teachers is likely to be less close than in elementary school, where students are primarily taught by the same teacher. The associations between emotional support and organizational and instructional support imply that emotional support operates "in the background", fostering student engagement.

Classroom size had a positive effect on teacher-rated student engagement. This is consistent with Malmberg et al. (2010), who found that larger secondary classrooms were more engaging than smaller ones. The positive effects of small classroom size on student engagement would appear to be particularly evident in the primary grades (Finn, Pannozzo, 
\& Achilles, 2003). In the present sample, while the classroom sizes were typical of those in Finnish schools, they were relatively small (mean 20 and range 9 students) compared to those in many other countries, which may explain the absence of negative associations between classroom size and student engagement. There may be a threshold in classroom size after which student engagement decreases.

The pattern of associations revealed differences in the perceptions of students and teachers regarding the classroom quality domains and behavioral engagement. From the students' perspective, engagement was mostly a function of emotional and instructional support. The students rated themselves as highly engaged in classrooms where high observed emotional support was associated with high instructional support. It seems that, in addition to caring, secondary school students expect teachers to provide teaching materials that clearly and systematically focus on the key ideas, along with timely feedback and scaffolding for students when necessary. Understandably, students desire challenging and fun learning activities which follow their own interests (Skinner \& Pitzer, 2012) in order to fully engage in learning. In the present sample, the mean values of the classroom quality domains were the lowest for instructional support. This suggests that teaching methods in Finnish secondary school classes are in need of development. For example, the use of instructional classroom dialogues, which teachers can be educated in, was conspicuously lacking (Lehesvuori, Viiri, \& Rasku-Puttonen, 2011).

From the perspectives of the adults (ratings of engagement by the teacher and the observers), the domain of classroom quality that was most strongly associated with engagement was organizational support. Teachers may regard organizational support as the most straightforward and effective way to engage students in meaningful academic learning and enhance students' social and moral growth (Evertson \& Weinstein, 2006). The result may, then, reflect teachers' beliefs concerning the importance of effectively engaging 
students in learning activities. From that perspective, engagement is a reciprocal process not only connected to student learning but one that has an influence on teachers as well (Skinner et al., 2008; Skinner \& Pitzer, 2012). Low student engagement threatens the teacher's basic needs (autonomy, competence, and relatedness), which may cause the teacher to become alienated from the students and diminish classroom quality.

Taken together, the present study showed that behavioral engagement is a contextual phenomenon which is associated with classroom quality. The classroom quality domains operate in concert and have potentially different roles with respect to student enagagement. Observed classroom organization best explained behavioral engagement. This is consistent with previous findings that students' time-on-task and learning results are optimal when management disruptions are rare (Ratcliff, Jones, Costner, Savage-David, \& Hunt, 2011). For example, Skinner and Belmont (1993) found that a clear and predictable classroom structure contributes to students' self-reported behavioral engagement in learning. Instructional support was associated with observed and student-rated engagement indicating that secondary school students exert more effort when instructed with teaching methods which foster their use of higher level thinking skills and enable deep processing of materials. Emotional support might have been stage setter for other interactions.

The findings of the present study suggest also that effective teaching may be best seen as a multidimensional construct. Students who see teachers as supportive are more likely to accept goals valued by teachers, such as engagement in learning activities. However, the present study provides evidence that being sensitive and responsive to students' needs and establishing a positive classroom climate is not enough to fully engage students. Clear expectations, effective behavior management, diverse learning formats, and maximized learning time (organizational support) along with teaching methods that promote higher level thinking skills and enable deep processing of materials (instructional support), must be 
provided by the teacher. The results are consistent with earlier findings indicating that high care and control are needed for optimal student engagement in the classroom (Thijs \& Verkuyten, 2009). These challenges call for teacher professional development (Pianta \& Hamre, 2009).

This study adds to the growing body of literature highlighting the importance of classroom processes, i.e. classroom quality, in students' school adjustment (e.g., Brackett et al., 2011; Reyes et al., 2012). Understanding of classroom processes is a pathway to enhancement of learning because daily processes characterized by positive interactions contribute to student engagement and, finally, to good learning results. This is especially important in the secondary school, as it is commonly known that student engagement declines after primary school (e.g., Skinner et al., 2008). Keeping in mind that student engagement is an outward manifestation of motivation, one possible explanation for the present results is provided by the motivational model. Drawing on self-determination theory (Deci \& Ryan, 2000; Deci \& Ryan, 2008), Connell and Wellborn (1991) presented a model where students need of relatedness, competence, and autonomy are taken into account. Engagement is fostered when there is a balance between warmth, structure, and autonomy in the classroom. Warmth contributes to students' sense of relatedness, structure affects competenece, and autonomy supports self-determinated motivation (autonomy) (Skinner \& Pitzer, 2012). Classroom processes that satisfy students' fundamental psychological needs form a motivational basis for active engagement.

\section{Practical implications}

Results of the present study have several practical implications. First, practitioners should be made aware of the importance of the classroom context in fostering student engagement. Students are not immune to what happens in the classroom. A focus on enhancing classroom quality is valuable because of its associations with increased student 
effort and positive effects on task behavior. Second, a relationship between classroom quality and behavioral engagement implies that in classrooms with a low level of behavioral engagement classroom-level interventions aimed at enhancing classroom quality may be needed. In schools where low engagement is a prevalent problem, school-wide practices should be implemented. At best, these efforts may result in an upward spiral which encourages efforts by the school personnel to facilitate positive classroom interactions. Finally, seeing teaching as a multidimensional construct in which the classroom quality domains may have different roles in fostering engagement, helps in directing interventions. Emotional support has practical relevance because it is associated with student engagement via organizational and instructional support. Being sensitive and responsive to students' needs, forming positive relationships with students, organizing the structure of classroom interactions in a way that maximizes learning time and prevents misbehavior, and providing dialogic, challenging, fun, and accessible learning tasks are important ways to promote engagement.

\section{Limitations}

First, the present study was based on a naturalistic, non-experimental, cross-sectional design, and hence the associations found cannot be taken as evidence of causality. The correlational nature of the study meant that we did not study effects but rather relations. The three domains of the CLASS-S instrument - emotional support, organizational support, and instructional support - were correlated, making it difficult to draw interpretations about the directions of the effects. Therefore, it is possible that models other than the one proposed here in which emotional support may carry the role of setting the stage for other classroom interactions are feasible. Future large-scale longitudinal studies should examine the effects of emotional support on organizational and instructional support to see whether they predict changes in students' behavioral engagement over time. 
Second, the sample consisted of 72 teaching cycles observed in nine secondary classrooms, making a total of four cycles observed per teacher. Typically, classroom quality varies during and between classes, although it seems to be rather stable in classrooms with younger children (Curby et al., 2010). Hence, interpretations would be on more solid ground if more observations were made over a longer period of time. A larger sample would also allow subject effects on behavioral engagement to be examined. There may be subjects that are by their nature behaviorally engaging (such as Home Economies). Future research should focus on the relations between subject differences, classroom quality, and student engagement in the secondary school.

Third, given that student engagement is a multidimensional construct (Fredricks, et al., 2004), the design would have been strengthened by including measures of affective and cognitive dimensions of student engagement. In the present study, the focus was solely on behavioral engagement. But there is cumulative evidence that other aspects of engagement are also associated with student classroom behavior and learning. Student-level observations would have given more person-oriented information of each individual student's engagement. This along with self-ratings of affective and cognitive engagement would allow combining student behavior in the classroom with his/her feelings and thoughts.

\section{Conclusion}

The present study is among the few studies to utilize systematic direct observations and multimethod assessments to investigate the effects of classroom quality on secondary students' behavioral engagement. The results indicated that students engagement in learning activities is high when organizational and instructional supports are high in the classroom. In addition, the results lend support to the view that emotional support has a role in setting the stage for organizational and instructional supports, and thus indirectly contributing to student engagement. 


\section{References}

Allen, J. P., Gregory, A., Mikami, A. Y., Lun, J., Hamre, B., \& Pianta, R. C. (2010). Observations of effective secondary school teaching: Predicting student achievement with the CLASS-S. Manuscript in preparation, University of Virginia, Charlottesville, $V A$. Unpublished manuscript.

Anderson, A., Hamilton, R., \& Hattie, J. (2004). Classroom climate and motivated behaviour in secondary schools. Learning Environments Research, 7(3), 211-225.

Appleton, J. J., \& Lawrenz, F. (2011). Student and teacher perspectives across mathematics and science classrooms: The importance of engaging contexts. School Science and Mathematics, 111(4), 143-155.

Archambault, I., Janosz, M., Fallu, J., \& Pagani, L. S. (2009). Student engagement and its relationship with early high school dropout. Journal of Adolescence, 32(3), 651-670.

Blatchford, P., Bassett, P., \& Brown, P. (2011). Examining the effect of class size on classroom engagement and teacher-pupil interaction: Differences in relation to pupil prior attainment and primary vs. secondary schools. Learning and Instruction, 21(6), 715-730.

Brackett, M. A., Reyes, M. R., Rivers, S. E., Elbertson, N. A., \& Salovey, P. (2011). Classroom emotional climate, teacher affiliation, and student conduct. Journal of Classroom Interaction, 46(1), 27-36.

Brok, P. den, Levy, J., Brekelmans, M., \& Wubbels, T. (2005). The effect of teacher interpersonal behaviour on students' subject-specific motivation. Journal of Classroom Interaction, 40(2), 20-33. 
Byrne, B. M. (2012). Structural equation modeling with Mplus : Basic concepts, applications, and programming. New York: Routledge.

Cohen, J. (1988). Statistical power analysis for the behavioral sciences (2nd ed.). Hillsdale, N.J: Lawrence Erlbaum.

Connell, J. P., \& Wellborn, J. G. (1991). Competence, autonomy, and relatedness: A motivational analysis of self-system processes. In M. R. Gunnar, \& L. A. Sroufe (Eds.), Self processes and development: The Minnesota symposia on child psychology (pp. 4377). Hillsdale (N.J.): Erlbaum.

Covell, K. (2010). School engagement and rights-respecting schools. Cambridge Journal of Education, 40(1), 39-51.

Curby, T. W., Grimm, K. J., \& Pianta, R. C. (2010). Stability and change in early childhood classroom interactions during the first two hours of a day. Early Childhood Research Quarterly, 25(3), 373-384.

Danielsen, A. G. (2009). School-related social support and students' perceived life satisfaction. Journal of Educational Research, 102(4), 303-318.

Deci, E. L., \& Ryan, R. M. (2000). The "what" and "why" of goal pursuits: Human needs and the self-determination of behavior. Psychological Inquiry, 11(4), 227-268.

Deci, E. L., \& Ryan, R. M. (2008). Self-determination theory: A macrotheory of human motivation, development, and health. Canadian Psychology, 49(3), 182-185.

Dorman, J. P. (2008). Using student perceptions to compare actual and preferred classroom environment in Queensland schools. Educational Studies, 34(4), 299-308. 
Eccles, J. S. (2004). Schools, academic motivation, and stage-environment fit. In R. M. Lerner, \& L. Steinberg (Ed.), Handbook of adolescent psychology (2nd ed., pp. 125153). Hoboken, NJ: John Wiley \& Sons.

Emmer, E. T., \& Stough, L. M. (2001). Classroom management: A critical part of educational psychology, with implications for teacher education. Educational Psychologist, 36(2), 103-112.

Evertson, C. M., \& Weinstein, C. S. (2006). Classroom management as a field of inquiry. In C. M. Evertson, \& C. S. Weinstein (Eds.), Handbook of classroom management: Research, practice, and contemporary issues (pp. 3-15). Mahwah, N.J: Lawrence Erlbaum.

Finn, J. D. (1989). Withdrawing from school. Review of Educational Research, 59(2), 117142.

Finn, J. D. (1993). School engagement and students at risk. Accessed August/10, 2011, from http://nces.ed.gov/pubs93/93470.pdf

Finn, J. D., \& Pannozzo, G. M. (1995). Disruptive and inattentive-withdrawn behavior and achievement among fourth graders. The Elementary School Journal, 95(5), 421-434.

Finn, J. D., Pannozzo, G. M., \& Achilles, C. M. (2003). The "why's" of class size: Student behavior in small classes. Review of Educational Research, 73(3), 321-368.

Finn, J. D., \& Rock, D. A. (1997). Academic success among students at risk for school failure. Journal of Applied Psychology, 82(2), 221-234. 
Finnish National Board of Education. (2010). Amendments and additions to the national core curriculum for basic education. Accessed 5/2, 2012, from http://www.oph.fi/download/132551_amendments_and_additions_to_national_core_curr iculum_basic_education.pdf

Fraser, B. J. (1998). Classroom environment instruments: Development, validity and applications. Learning Environments Research, 1(1), 7-33.

Fraser, B. J. Aldridge, J. M., \& Adolphe, S. F. (2010). A cross-national study of secondary science classroom environments in Australia and Indonesia. Research in Science Education, 40(4), 551-571.

Fredricks, J. A., Blumenfeld, P. C., \& Paris, A. H. (2004). School engagement: Potential of the concept, state of the evidence. Review of Educational Research, 74(1), 59-109.

Furrer, C., \& Skinner, E. (2003). Sense of relatedness as a factor in children's academic engagement and performance. Journal of Educational Psychology, 95(1), 148-162.

Gettinger, M., \& Walter, M. J. (2012). Classroom strategies to enhance academic engaged time. In S. L. Christenson, A. L. Reschly \& C. Wylie (Eds.), Handbook of research on student engagement (pp. 653-673). New York: Springer.

Gibbs, R., \& Poskitt, J. (2010). Student engagement in the middle years of schooling (years 7-10): A literature review. Accessed September/2, 2011, from http://www.educationcounts.govt.nz/_data/assets/pdf_file/0010/74935/940_StudentEngagement-19052010.pdf 
Gilstrap, S. C. (2003). An evaluation of the effectiveness of federal class size reduction in the Los Angeles unified school district: Does class size influence teacher-student interaction in secondary classrooms?. Los Angeles Unified School District Program Evaluation and Research Branch: Planning Assessment and Research Division Publication No. 141.

Glanville, J. L., \& Wildhagen, T. (2007). The measurement of school engagement: Assessing dimensionality and measurement invariance across race and ethnicity. Educational \& Psychological Measurement, 67(6), 1019-1041.

Hardman, F. (2008). Teachers' use of feedback in whole-class and group-based talk. In N. Mercer, \& S. Hodgkinson (Eds.), Exploring talk in schools: Inspired by the work of Douglas Barnes (pp. 131-150). Los Angeles (Calif.): SAGE.

Hattie, J. A. C. (2009). Visible learning: A synthesis of over 800 meta-analyses relating to achievement. London: Routledge.

Klem, A. M., \& Connell, J. P. (2004). Relationships matter: Linking teacher support to student engagement and achievement. Journal of School Health, 74(7), 262-273.

Lehesvuori, S., Viiri, J., \& Rasku-Puttonen, H. (2011). Introducing dialogic teaching to science student teachers. Journal of Science Teacher Education, 22(8), 705-727.

Li, Y., Lerner, J. V., \& Lerner, R. M. (2010). Personal and ecological assets and academic competence in early adolescence: The mediating role of school engagement. Journal of Youth and Adolescence, Electronic; 39(7), 801-815.

Libbey, H. P. (2004). Measuring student relationships to school: Attachment, bonding, connectedness, and engagement. Journal of School Health, 74(7), 274-283. 
MacKinnon, D. P., Lockwood, C. M., \& Williams, J. (2004). Confidence limits for the indirect effect: Distribution of the product and resampling methods. Multivariate Behavioral Research, 39(1), 99-28.

Malecki, C. K., \& Demaray, M. K. (2003). What type of support do they need? Investigating student adjustment as related to emotional, informational, appraisal, and instrumental support. School Psychology Quarterly, 18(3), 231-252.

Malmberg, L., Hagger, H., Burn, K., Mutton, T., \& Colls, H. (2010). Observed classroom quality during teacher education and two years of professional practice. Journal of Educational Psychology, Electronic; 102(4), 916-932.

Marks, H. M. (2000). Student engagement in instructional activity: Patterns in the elementary, middle, and high school years. American Educational Research Journal, $37(1), 153-184$.

McGraw, K. O., \& Wong, S. P. (1996). Forming inferences about some intraclass correlation coefficients. Psychological Methods, Electronic; 1(1), 30-46.

Mercer, N., \& Littleton, K. (2007). Dialogue and the development of children's thinking: A sociocultural approach. Abingdon and New York: Routledge.

Mitchell, D. R. (2008). What really works in special and inclusive education: Using evidence-based teaching strategies. New York: Taylor \& Francis.

Muthén, L. K., \& Muthén, B. O. (1998-2010). Mplus User's guide. (6th ed.). Los Angeles, CA: Muthén \& Muthén. 
Patrick, H., \& Ryan, A. M. (2007). Early adolescents' perceptions of the classroom social environment, motivational beliefs, and engagement. Journal of Educational Psychology, 99(1), 83-98.

Perry, N. E., Turner, J. C., \& Meyer, D. K. (2006). Classroom as contexts for motivating learning. In P. A. Alexander, \& P. H. Winnie (Eds.), Handbook of educational psychology (vol. 2). (pp. 327-348). Mahwah, NJ: Lawrence Erlbaum.

Pianta, R. C., \& Allen, J. P. (2007). Building capacity for positive youth development in secondary school classrooms: Changing teachers' interactions with students. In M. Shinn, \& H. Yoshikawa (Eds.), Toward positive youth development: Transforming schools and community programs. (pp. 21-39). New York: Oxford University Press.

Pianta, R. C., \& Hamre, B. K. (2009). Classroom processes and positive youth development: Conceptualizing, measuring, and improving the capacity of interactions between teachers and students. New Directions for Youth Development, (121), 33-46.

Pianta, R. C., Hamre, B. K., \& Allen, J. P. (2012). Teacher-student relationships and engagement: Conceptualizing, measuring, and improving the capacity of classroom interactions. In S. L. Christenson, A. L. Reschly \& C. Wylie (Eds.), Handbook of research on student engagement (pp. 365-386)

Pianta, R. C., Hamre, B. K., \& Mintz, S. L. (2010). The CLASS-secondary manual. Unpublished measure. Charlottesville, VA: University of Virginia.

Pianta, R. C., La Paro, K. M., \& Hamre, B. K. (2008). The Classroom Assessment Scoring System. Manual, pre-K. Baltimore: Brookes. 
Ratcliff, N. J., Jones, C. R., Costner, R. H., Savage-David, E., \& Hunt, G. H. (2011). The impact of misbehavior on classroom climate. Education Digest, 77(2), 16-20.

Reyes, M. R., Brackett, M. A., Rivers, S. E., White, M., \& Salovey, P. (2012). Classroom emotional climate, student engagement, and academic achievement. Journal of Educational Psychology, Electronic; 46(1), 27-36.

Richman, J. M., Rosenfeld, L. B., \& Bowen, G. L. (1998). Social support for adolescents at risk of school failure. Social Work, 43(4), 309-323.

Rimm-Kaufman, S., Fan, X., Chiu, Y., \& You, W. (2007). The contribution of the responsive classroom approach on children's academic achievement: Results from a three year longitudinal study. Journal of School Psychology, 45(4), 401-421.

Ryan, A. M., \& Patrick, H. (2001). The classroom social environment and changes in adolescents' motivation and engagement during middle school. American Educational Research Journal, 38(2), 437-460.

Sahlberg, P. (2007). Education policies for raising student learning: The Finnish approach. Journal of Education Policy, 22(2), 147-171.

Skinner, E.A., Furrer, C. J., Marchand, G., \& Kindermann, T. A. (2008). Engagement and disaffection in the classroom: Part of a larger motivational dynamic? Journal of Educational Psychology, 100(4), 765-781.

Skinner, E. A., \& Belmont, M. J. (1993). Motivation in the classroom: Reciprocal effects of teacher behavior and student engagement across the school year. Journal of Educational Psychology, 85(4), 571-581. 
Skinner, E. A., Kindermann, T. A., \& Furrer, C. J. (2009). A motivational perspective on engagement and disaffection: Conceptualization and assessment of children's behavioral and emotional participation in academic activities in the classroom. Educational \& Psychological Measurement, 69(3), 493-525.

Skinner, E. A., \& Pitzer, J. R. (2012). Developmental dynamics of student engagement, coping, and everyday resilience. In S. L. Christenson, A. L. Reschly \& C. Wylie (Eds.), Handbook of research on student engagement (pp. 21-44). New York: Springer.

Suldo, S. M., Friedrich, A. A., White, T., Farmer, J., Minch, D., \& Michalowski, J. (2009). Teacher support and adolescents' subjective well-being: A mixed-methods investigation. School Psychology Review, 38(1), 67-85.

Thijs, J., \& Verkuyten, M. (2009). Students' anticipated situational engagement: The roles of teacher behavior, personal engagement, and gender. Journal of Genetic Psychology, $170(3), 268-286$.

Thuen, E., \& Bru, E. (2000). Learning environment, meaningfulness of schoolwork and ontask-orientation among Norwegian 9th grade students. School Psychology International, 21(4), 393-413.

Waldrip, B. (2009). Identifying exemplary science teachers through students' perceptions of their learning environment. Learning Environments Research, 12(1), 1-13.

Walker, C. O., \& Greene, B. A. (2009). The relations between student motivational beliefs and cognitive engagement in high school. Journal of Educational Research, 102(6), 463472. 
Wang, M., Willett, J. B., \& Eccles, J. S. (2011). The assessment of school engagement: Examining dimensionality and measurement invariance by gender and race/ethnicity. Journal of School Psychology, 49(4), 465-480.

Wang, M., \& Eccles, J. S. (2012). Adolescent behavioral, emotional, and cognitive engagement trajectories in school and their differential relations to educational success. Journal of Research on Adolescence (Blackwell Publishing Limited), 22(1), 31-39.

Wigfield, A., Eccles, J. S., Schiefele, U., Roeser, R., \& Davis-Kean, P. (2006). Development of achievement motivation. In W. Damon (Series Ed. ) \& N. Eisenberg (Vol. Ed.), Handbook of child psychology: Vol. 3. social, emotional, and personality development (6th ed., pp. 933-1002). New York: John Wiley.

Woolley, M. E., \& Bowen, G. (2007). In the context of risk: Supportive adults and the school engagement of middle school students. Family Relations, 56(1), 92-104. 
Table 1 Descriptive statistics and correlations among classroom quality domains and dimensions

\begin{tabular}{|c|c|c|c|c|c|c|c|c|c|c|c|}
\hline & 1. & 2. & 3. & 4. & 5. & 6. & 7. & 8. & 9. & 10. & 11. \\
\hline Emotional Support & $.85^{* * * *}$ & $-.58 * * *$ & $.80 * * *$ & $.78 * * *$ & $.35 * * *$ & $.27 * * *$ & $.72 * * *$ & $.61 * * *$ & $.61 * * *$ & $.74 * * *$ & $.70 * * *$ \\
\hline 1. Positive Climate & & $-.48 * * *$ & $.68 * * *$ & $.48^{* * *}$ & $.36 * * *$ & $.32 * * *$ & $.57 * * *$ & $.44 * * *$ & $.35 * * *$ & $.56^{* * *}$ & $.45^{* * *}$ \\
\hline 2. Negative Climate & & & $-.37 * * *$ & $-.24 * * *$ & $-.32 * * *$ & $-.18 * *$ & $-.24 * * *$ & $-.37 * * *$ & $-.30 * * *$ & $-.35 * * *$ & $-.29 * * *$ \\
\hline $\begin{array}{l}\text { 3. Teacher } \\
\text { Sensitivity }\end{array}$ & & & & $.45^{* * *}$ & $.32 * * *$ & $.35 * * *$ & $.59 * * *$ & $.46^{* * *}$ & $.44 * * *$ & $.52 * * *$ & $.55 * * *$ \\
\hline $\begin{array}{l}\text { 4. Regard for Adol. } \\
\text { Perspectives }\end{array}$ & & & & & $.18^{* *}$ & .03 & $.69 * * *$ & $.60 * * *$ & $.68 * * *$ & $.72 * * *$ & $.70 * * *$ \\
\hline Classroom Organization & $.48 * * *$ & $-.33 * * *$ & $.47 * * *$ & $.34 * * *$ & $.86 * * *$ & $.78 * * *$ & $.75^{* * *}$ & $.48 * * *$ & $.40 * * *$ & $.32 * * *$ & $.25 * * *$ \\
\hline $\begin{array}{l}\text { 5. Behavior } \\
\text { Management }\end{array}$ & & & & & & $.54 * * *$ & $.46^{* * *}$ & $.25 * * *$ & $.18^{* *}$ & $.11^{*}$ & .02 \\
\hline 6. Productivity & & & & & & & $.44 * * *$ & $.30 * * *$ & $.20 * * *$ & .10 & .06 \\
\hline $\begin{array}{l}\text { 7. Instructional } \\
\text { Learning formats }\end{array}$ & & & & & & & & $.57 * * *$ & $.56 * * *$ & $.64 * * *$ & $.62 * * *$ \\
\hline
\end{tabular}




\begin{tabular}{|c|c|c|c|c|c|c|c|c|c|c|c|}
\hline & 1. & 2. & 3. & 4. & 5. & 6. & 7. & 8. & 9. & 10. & 11. \\
\hline Instructional Support & $.52 * * *$ & $-.38 * * *$ & $.56 * * *$ & $.75 * * *$ & $.15^{* *}$ & $.17 * *$ & $.67 * * *$ & $.87 * * *$ & $.89 * * *$ & $.90 * * *$ & $.86 * * *$ \\
\hline $\begin{array}{l}\text { 8. Content } \\
\text { Understanding }\end{array}$ & & & & & & & & & $.79 * * *$ & $.75 * * *$ & $.61 * * *$ \\
\hline $\begin{array}{l}\text { 9. Analysis \& } \\
\text { Problem Solving }\end{array}$ & & & & & & & & & & $.72 * * *$ & $67 * * *$ \\
\hline $\begin{array}{l}\text { 10. Quality of } \\
\text { Feedback }\end{array}$ & & & & & & & & & & & $.75 * * *$ \\
\hline \multicolumn{12}{|l|}{ 11. Instr. dialogues } \\
\hline$M$ & 4.74 & 1.47 & 4.22 & 3.82 & 4.18 & 4.37 & 4.36 & 3.95 & 2.92 & 3.48 & 3.03 \\
\hline$S D$ & .99 & .74 & .97 & 1.32 & 1.53 & 1.22 & 1.23 & 1.26 & 1.38 & 1.32 & 1.44 \\
\hline
\end{tabular}

Note. ${ }^{* * *} \mathrm{p}<.001 .{ }^{* *} \mathrm{p}<.01 .{ }^{*} \mathrm{p}<.05 .2$-tailed Spearman's rho. 
Table 2 Correlations between classroom quality domains and engagement measures



Note. $* * * \mathrm{p}<.001 . * * \mathrm{p}<.01 . * \mathrm{p}<.05 .2$-tailed Spearman's rho. 
Table 3 Classroom differences in classroom quality domains and students' behavioral engagement in learning: Results of the ANOVA

\begin{tabular}{cllc}
\hline & $F$ & $\begin{array}{l}\text { Ranges of } \\
\text { mean scores }\end{array}$ & $\eta^{2}$ \\
Classroom quality & $F(8,63)=8.00^{* * *}$ & $3.68-5.56$ & .50 \\
Emotional support & $F(8,63)=10.89 * * *$ & $2.83-5.58$ & .58 \\
$\begin{array}{l}\text { Classroom } \\
\text { organization } \\
\text { Instructional support }\end{array}$ & $F(8,63)=10.29 * * *$ & $2.06-5.28$ & .56 \\
& & & \\
& & $\begin{array}{l}\text { Ranges of } \\
\text { mean scores }\end{array}$ & \\
Student engagement & & & \\
Observed engagement & $F(8,63)=6.99 * * *$ & $2.43-5.18$ & .47 \\
$\begin{array}{l}\text { Student-reported } \\
\text { engagement }\end{array}$ & $\mathrm{F}(8,100)=2.82^{* * *}$ & $2.93-4.08$ & .18 \\
\hline
\end{tabular}

Note. $* * * \mathrm{p}<.001 . * * \mathrm{p}<.01 . * \mathrm{p}<.05$. 
CLASSROOM QUALITY



Fig. 1 Relationship between classroom quality domains and students' engagement

Note. All path coefficients are standardized. $* * * \mathrm{p}<.001 . * * \mathrm{p}<.01 . * \mathrm{p}<.05 . \dagger \mathrm{p}<.10$. One-tailed. 